4. Lorence DP, Park H, Fox S. Assessing health consumerism on the Web: a demographic profile of information-seeking behaviors. J Med Syst 2006:30:251-258.

5. McMullan M. Patients using the Internet to obtain health information: how this affects the patient-health professional relationship. Patient Educ Couns 2006;63:24-28.

6. Hall S, Abramsky L, Marteau TM. Health professionals' report of information given to parents following the prenatal diagnosis of sex chromosome anomalies and outcomes of pregnancies; a pilot study. Prenat Diagn 2003;23:535-538.

7. Marteau TM, Nippert I, Hall S, et al.; DADA Study Group. Decision-making after diagnosis of fetal abnormality. Outcomes of pregnancies diagnosed with Klinefelter syndrome: the possible influence of health professionals. Prenat Diagn 2002;22:562-566.

doi:10.1038/gim.2012.32

\section{Response to Pieters et al.}

To the Editor: We wish to thank Pieters, Kooper, Smits, and Feuth for their interest in our review. We appreciate their thoughtful comments and the important factors raised in their letter "Considering Factors Affecting the Parental Decision to Abort After a Prenatal Diagnosis of a Sex Chromosome Abnor-

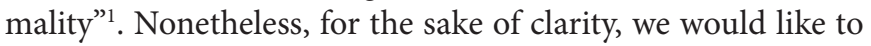
point out that our review ${ }^{2}$ extends beyond an analysis of demographic factors to include nondemographic variables such as type of sex chromosome abnormality and parents' fears.

No doubt the confounding factors raised by Pieters and colleagues (reason for referral, the role of the Internet, and qualifications of counseling providers) are extremely important for more fully understanding decisions to continue or terminate a sex chromosome abnormality-affected pregnancy. Unfortunately, these factors did not emerge as findings in the studies we reviewed, as they were not sufficiently explored in this body of work. Therefore, we thank Pieters and colleagues for helping to highlight and reinforce both this gap and our call for betterquality studies. To date, assessments of decisions surrounding a sex chromosome abnormality-affected pregnancy have been limited in their ability to identify the multiple factors shaping these decisions, the nuanced variability within those factors, and the complex interactions among them. Studies that (i) tap into the context of decision-making, (ii) examine how parents obtain information on their own through the Internet, and (iii) explore the role played by various types of service providers, in-depth-are urgently needed!

Moreover, as we argue in our review, studies of better methodological quality are also missing from this body of literature. Given the multifactor nature of the topic, it makes little sense to capture complex associations among factors and decisions using descriptive or bivariate statistical analyses without controlling for confounders or covariates. Also missing from this literature are qualitative studies that portray parents' points of view and voices, directly.

Finally, given the below-average methodological quality scores of most studies in the review, we chose not to report each study's score individually. These are available, however, upon request to the authors.

\section{DISCLOSURE}

The authors declare no conflict of interest.

Kwon Chan Jeon, MS ${ }^{1}$, Lei-Shih Chen, PhD, $\mathrm{CHES}^{1}$ and Patricia Goodson, $\mathrm{PhD}^{1}$

${ }^{1}$ Department of Health \& Kinesiology, Texas A\&M University, College Station, Texas, USA.E-mail:kc_jeon@hlkn.tamu.edu

\section{REFERENCES}

1. Pieters JJPM, Kooper AJA, Smits APT, Feuth TB. Considering factors affecting the parental decision to abort after a prenatal diagnosis of a sex chromosome abnormality. Genet Med 2012;14:558-559.

2. Jeon KC, Chen LS, Goodson P. Decision to abort after a prenatal diagnosis of sex chromosome abnormality: a systematic review of the literature. Genet Med 2012;14:27-38.

doi:10.1038/gim.2012.33 